\title{
CULTURAL IMPACTS ON ORGANIZATIONAL KNOWLEDGE SHARING
}

\author{
OvARI, N.; GAAL, Z. \& SZABO, L.
}

Abstract: Why do people share their knowledge? People choose their actions depending on their beliefs that originated from previous experiences. Motivating knowledge sharing behaviours is an important first step to instilling a knowledgesharing culture. In this paper, we present a Hungarian Research, which defines factors that describe Knowledge Management practice of an organization and we state that certain organizational cultures are more receptive to Knowledge Management programs than others are.

Key words: Knowledge, Knowledge Management, Knowledge Sharing, Organizational Culture
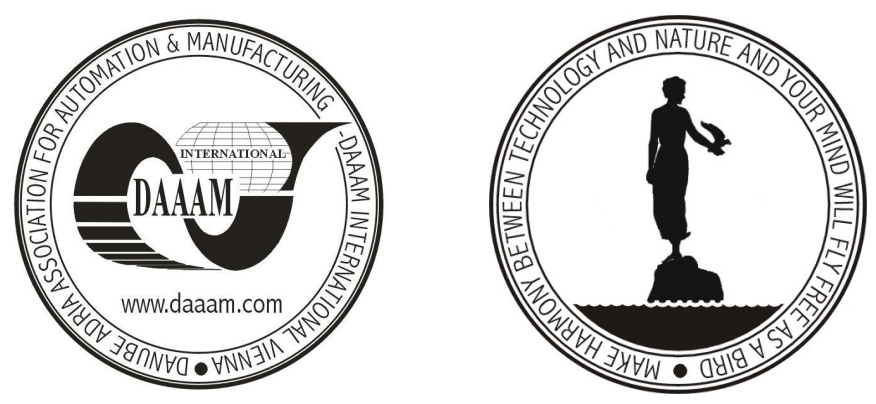

Authors' data: PhD. Ovari, N[ora]*; Prof. Gaal, Z[oltan]**; Dr. Szabo, L[ajos]**, * University of Veszprém, H-9700 Szombathely, Vörösmarty u. 17., Hungary, ** University of Pannonia, H-8200, Veszprem, Egyetem u. 10, Hungary, obermayer.kovacs@doc.hu, gaal@gtk.uni-pannon.hu, szabola@gtk.uni-pannon.hu

This Publication has to be referred as: Ovari, N.; Gaal, Z. \& Szabo, L. (2007). Cultural impacts on organizational knowledge sharing, Chapter 15 in DAAAM International Scientific Book 2007, B. Katalinic (Ed.), Published by DAAAM International, ISBN 3-901509-60-7, ISSN 1726-9687, Vienna, Austria

DOI: $10.2507 /$ daaam.scibook.2007.15 